\title{
LSM Microelectrodes: Kinetics and Surface Composition
}

Hansen, Karin Vels; Norrman, Kion; Jacobsen, Torben; Wu, Yuehua; Mogensen, Mogens Bjerg

Published in:

Journal of The Electrochemical Society

Link to article, DOI:

10.1149/2.0361510jes

Publication date:

2015

Document Version

Peer reviewed version

Link back to DTU Orbit

Citation (APA):

Hansen, K. V., Norrman, K., Jacobsen, T., Wu, Y., \& Mogensen, M. B. (2015). LSM Microelectrodes: Kinetics and Surface Composition. Journal of The Electrochemical Society, 162(10), F1165-F1174.

https://doi.org/10.1149/2.0361510jes

\section{General rights}

Copyright and moral rights for the publications made accessible in the public portal are retained by the authors and/or other copyright owners and it is a condition of accessing publications that users recognise and abide by the legal requirements associated with these rights.

- Users may download and print one copy of any publication from the public portal for the purpose of private study or research.

- You may not further distribute the material or use it for any profit-making activity or commercial gain

- You may freely distribute the URL identifying the publication in the public portal

If you believe that this document breaches copyright please contact us providing details, and we will remove access to the work immediately and investigate your claim. 


\title{
LSM Microelectrodes: Kinetics and Surface Composition
}

Karin Vels Hansen ${ }^{\mathrm{a}}$, Kion Norrman ${ }^{\mathrm{a}}$, Torben Jacobsen ${ }^{\mathrm{b}}$, Yuehua $\mathrm{Wu}^{\mathrm{a}}$, Mogens Bjerg Mogensen ${ }^{\mathrm{a}}$

${ }^{a}$ Department of Energy Conversion and Storage, Technical University of Denmark, Frederiksborgvej 399, Roskilde, DK-4000 Roskilde, Denmark

${ }^{\mathrm{b}}$ Department of Chemistry, Technical University of Denmark, Kemitorvet Build. 207, DK-2800 Kgs. Lyngby, Denmark

\begin{abstract}
Lanthanum strontium manganite microelectrodes with the nominal composition of $\left(\mathrm{La}_{0.75} \mathrm{Sr}_{0.25}\right)_{0.95} \mathrm{MnO}_{3}$ and a thickness of ca $500 \mathrm{~nm}$ was electrochemically characterized in situ at temperatures from 660 to $850{ }^{\circ} \mathrm{C}$ using a controlled atmosphere high temperature scanning probe microscope. Impedance spectroscopy and cyclic voltammetry were performed on electrodes with diameters of 20-100 $\mu \mathrm{m}$ in oxygen, air and nitrogen both at open circuit voltage and at anodic and cathodic polarization. In situ conductance mapping, ex situ surface analysis by time-of-flight secondary ion mass spectrometry, and scanning electron microscopy were performed to observe electrical, chemical and structural changes on the microelectrodes.
\end{abstract}

\section{Introduction}


Microelectrodes are due to their well-defined geometry considered very suitable for detailed studies on solid oxide fuel cell (SOFC) electrodes which otherwise possess a complex microstructure. There has been quite a number of research works carried out on oxygen reduction reaction kinetics on LSM microelectrodes. Brichzin et al. (1) studied the dependence on diameter and thickness of the polarization resistance $\left(R_{p}\right)$ of lanthanum strontium manganite (LSM) microelectrodes on YSZ prepared by pulsed laser deposition (PLD) and photolithography. The electrical characteristics of the LSM microelectrodes were measured by impedance spectroscopy and i-V measurements at $800{ }^{\circ} \mathrm{C}$ in air. From the dependency of $R_{p}$ on the microelectrode diameter it was concluded that at cathodic polarization the entire electrode area was active, whereas the electrode reaction was confined to the triple phase boundary in the anodic region. Later Fleig et al. (2) studied atmosphere dependence of $R_{p}$ for $\left(\mathrm{La}_{0.8} \mathrm{Sr}_{0.2}\right)_{0.92} \mathrm{MnO}_{3}$ microelectrodes on YSZ with diameters ranging from 20$100 \mu \mathrm{m}$ and thicknesses of 100 or $250 \mathrm{~nm}$. Electrochemical characterization was carried out at $800{ }^{\circ} \mathrm{C}$ in four different atmospheres, with $\mathrm{pO}_{2}$ ranging from $2 \times 10^{-5}$ bar to 1 bar. They concluded that the total $R_{p}$ consists of contributions from oxygen exchange on the LSM surface and ion transport through the LSM electrode. The oxygen exchange resistance decreases with increasing $p \mathrm{O}_{2}$ while the transport resistance increases with increasing $\mathrm{pO}_{2}$. Accordingly, the rate-limiting step of the oxygen reduction reaction depends on the partial pressure with the surface resistance being limiting for low $\mathrm{pO}_{2}$ and ion transport for high $\mathrm{pO}_{2}$. la $\mathrm{O}^{\prime}$ et al. $(3,4)$ studied thickness dependence of the polarization resistance of LSM microelectrodes. They concluded that the surface oxygen exchange and mixed bulk/triple phase boundary (TPB) charge transfer process control oxygen reduction reaction kinetics at high and low temperatures, respectively.

Previously (5) initial results on electrochemical characterization of the microelectrodes were reported. In the present work we investigate in more detail the influence of both $\mathrm{pO}_{2}$ and polarization on the electrochemical characteristics of LSM microelectrodes with a dedicated 
controlled atmosphere high temperature scanning probe microscope (CAHT-SPM) where in operando conditions can be obtained. Before and after the measurement sequence the surface composition of the electrodes was analyzed ex situ by scanning electron microscopy (SEM) and time-of-flight secondary ion mass spectrometry (TOF-SIMS) to investigate electrochemically and thermally induced compositional and microstructural changes. Changes in the conductance from the as sintered microelectrodes to the electrochemically characterized were mapped by CAHT-SPM at $650^{\circ} \mathrm{C}$.

\section{Experimental}

Preparation of LSM microelectrodes. - Circular substrates of 8 mol\% yttria stabilized zirconia (YSZ) (TZ8Y, Tosoh Corporation) were sintered at $1500{ }^{\circ} \mathrm{C}$ in air for 2 hours. A final diameter of $10 \mathrm{~mm}$ was obtained. The substrate surface was polished before deposition of an LSM film by PLD. The LSM target (fabricated in-house) used for the deposition had a nominal composition of $\left(\mathrm{La}_{0.75} \mathrm{Sr}_{0.25}\right)_{0.95} \mathrm{MnO}_{3}$ and was sintered at $1200{ }^{\circ} \mathrm{C}$ in air for 2 hours. Prior to the deposition, the YSZ substrates were heated to $650{ }^{\circ} \mathrm{C}$ with a rate of $10^{\circ} \mathrm{C}$ per minute under vacuum conditions $\left(1 \times 10^{-6} \mathrm{mbar}\right)$. The deposition took place at a repetition rate of $15 \mathrm{~Hz}$, a target-substrate distance of $5.5 \mathrm{~cm}$, and a laser fluence of $4 \mathrm{~J} \mathrm{~cm}^{-2}$. The thickness of the LSM film was measured by a Dektak profilometer (V200-Si, Veeco) to around 500 nm (Figure 1a). Scanning electron microscopy (SEM, Zeiss Supra) of the cross section of the LSM film (Figure 1b) shows that the deposited film is dense and gas tight. The deposited LSM film has a grain size of less than $100 \mathrm{~nm}$. 
The LSM microelectrodes were prepared by photolithography (6). After etching in HCl, differently sized circular LSM microelectrodes were left in the center of the YSZ substrate along with areas $\sim 2 \times 2 \mathrm{~mm}$ LSM for counter electrodes between the microelectrodes and the edge of the pellet. As the counter electrode area is 500 times that of the largest microelectrodes the counter electrode polarization is considered negligible in the electrochemical measurements.

The LSM microelectrodes were sintered at $1000{ }^{\circ} \mathrm{C}$ in air for 5 hours. The sizes of the microelectrodes were measured by optical microscopy, and they were further characterized by SEM (Zeiss Supra) without carbon coating by using an acceleration voltage of $3 \mathrm{kV}$ to avoid charging. Xray diffraction showed only peaks corresponding to YSZ and LSM, and the LSM phase was well crystallized. Atomic force microscopy (AFM, DualScope DS95-50, DME Danish Micro Engineering A/S, Denmark) was used to characterize the surface morphology of the microelectrodes. Figure 2 presents AFM images of a $50 \mu$ m diameter LSM microelectrode. The images confirm that the LSM microelectrodes are dense. The outer $\sim 2-4 \mu \mathrm{m}$ of the microelectrodes slope towards the substrate with an angle of $5-10^{\circ}$.

Electrochemical Characterization. - The electrochemical measurements were carried out using a CAHT-SPM (Figure 3) (CAHT-2, DME Danish Micro Engineering A/S, Denmark). CAHT-2 is described in details elsewhere (7) and works basically as a normal atomic force microscope where the probe can either be scanned over an area or it can be placed in a selected location to perform local measurements, such as electrochemical impedance spectroscopy. The sample can be heated to around $850{ }^{\circ} \mathrm{C}$. The experiments were conducted over several days and in between the experiments the samples were cooled to room temperature. The heating and cooling rate was always $20^{\circ} \mathrm{C} / \mathrm{min}$. The sample temperature was measured during a separate calibration test by a thermocouple placed on the sample surface with an estimated error of $\pm 15^{\circ} \mathrm{C}$. The sample chamber can be flowed with a controlled atmosphere, which in the present experiments was either dry nitrogen (99.999\% $\mathrm{N}_{2}$ ), dry 
oxygen $\left(99.9 \% \mathrm{O}_{2}\right)$ or a mixture of $80 \% \mathrm{~N}_{2}$ and $20 \% \mathrm{O}_{2}$ to produce clean, artificial air. A $\mathrm{pO}_{2}$ monitor is connected to the gas outlet and the gas composition could thus be verified based on the resulting voltage. Dry nitrogen results in a $\mathrm{pO}_{2}$ of $1 \times 10^{-4}$ bar. The sample chamber pressure is always $1 \mathrm{~atm}$. In-house fabricated conductive probes with a diameter of up to a few micrometers, made from a $\mathrm{Pt}_{0.8} \mathrm{Ir}_{0.2}$ alloy, were used to contact selected LSM microelectrodes. The electrical characteristics of the LSM microelectrodes were determined by performing cyclic voltammetry where the voltage was swept from $0 \mathrm{~V}$ to $350 \mathrm{mV}$ to $-350 \mathrm{mV}$ and back to $0 \mathrm{mV}$ with a sweep rate of $1 \mathrm{mV}^{-\mathrm{s}}$, followed by electrochemical impedance spectroscopy under polarization. A series of impedance spectra was acquired at polarizations ranging from $100 \mathrm{mV}$ to $350 \mathrm{mV}$ or $-100 \mathrm{mV}$ to $350 \mathrm{mV}$ in steps of $50 \mathrm{mV}$. The cyclic voltammetry and impedance spectroscopy was performed with a Gamry Femtostat potentiostat in the frequency range from $80 \mathrm{kHz}$ to $0.1 \mathrm{~Hz}$, or lower, with 6 points per decade and an AC voltage of $10 \mathrm{mV}$. As a consequence of the uncertainty on the surface temperatures, the temperature values reported previously (5) have been rounded off in the present paper. Also, the impedance measurements have been reevaluated on the basis of a simplified equivalent circuit.

TOF-SIMS analyses. - The TOF-SIMS analyses were performed using a TOF-SIMS IV (ION-TOF GmbH, Münster, Germany). Ion images were acquired covering $150 \times 150 \mu \mathrm{m}^{2}$ and $50 \times 50 \mu \mathrm{m}^{2}$ areas of the sample surfaces by employing 100 -ns pulses of $25 \mathrm{keV} \mathrm{Bi}^{+}$at a repetition rate of $10 \mathrm{kHz}$ yielding a target current of $\leq 10 \mathrm{fA}$ with a $\sim 200 \mathrm{~nm}$ image resolution. A $750 \times 750 \mu \mathrm{m}^{2}$ surface area surrounding each analysis position was sputter cleaned prior to analysis using $30 \mathrm{nA}$ of $3 \mathrm{keV} \mathrm{Xe}^{+}$ for 45 seconds in order to remove adventitiously adsorbed hydrocarbons on the surfaces. Electron bombardment (20 eV) was used to minimize charge build-up at the surface. Desorbed secondary ions were accelerated to $2 \mathrm{keV}$, mass analyzed in the flight tube, and post-accelerated to $10 \mathrm{keV}$ before detection. 
Conductance mapping. - The conductance of the microelectrodes was measured with CAHT-2 or CAHT-1 (8). The samples were mounted with springs on the hot plate and a counter electrode was attached to a corner of the sample. Topography and conductance maps were obtained simultaneously in contact mode with a Pt-Ir probe at lowest possible force at a surface temperature of $650{ }^{\circ} \mathrm{C}$ in air. The conductance maps were acquired by applying an AC signal at $10 \mathrm{kHz}$ and 0.5 V rms to the probe and measuring the resulting current with a Stanford SR830 lock-in amplifier. A $1 \mathrm{M} \Omega$ resistor was inserted after the counter electrode to avoid overload of the current amplifier. The measured conductance is defined as the three-dimensional "10 kHz conductance" from the CAHT-SPM tip though the LSM layer (if on the microelectrode) across the interface and into the electrolyte. In Figure 4 the current distributions in the cases of measurements on the electrolyte and on the surface of a highly conducting microelectrode is shown. Since the volume elements along the current lines are in series, their contributions to the overall resistance are weighted by the local current density times the resistivity of the elements. Thus, a point measurement on the electrolyte surface mainly reflects the conductivity of a volume element below the surface with dimensions of a few radii of the tip-surface contact area. In contrast, on the microelectrode the high lateral conductance will result in a current distribution on the electrode-electrolyte interface that is almost uniform except along the TPB, irrespective of the position of tip.

The intension with these measurements is to map the electrode surface and near surroundings in order to give an impression of how the "simple" conductivity from all TPB points, with a minimum of Faradaic contributions to the resistance, is distributed over the electrode surface before and after the experiments. The conductance, $\sigma$, was calculated as the ratio of the in-phase current and the output voltage. Although this quantity includes the effect of the series resistor, it is used in the following to avoid infinite conductances in the graphs. The actual tip-surface conductance, $\sigma$, can be calculated from the $\sigma$ values as $\sigma=1 /\left(1 / \sigma-10^{6} \Omega\right)$. 


\section{Results}

Impedance at Open Circuit Voltage (OCV). - As described by Fleig et al. (2), the overall oxygen reduction reaction on thin LSM electrodes is a combination of two reaction paths. One is the surface reaction path where oxygen which is dissociated and reduced to oxide ions on the LSM-gas interface, diffuses through the LSM and is transferred to the YSZ electrolyte, and second is the parallel TPB path that prior to the charge transfer reaction may involve surface diffusion of adsorbed species to the TPB. A detailed description of these reactions would result in a fairly complex equivalent circuit. However, the actual spectra are relatively simple and do not justify the presence of more than a few components. Therefore the reduced circuit shown in Figure $5 \mathrm{a}$ is used in the present work. In this circuit the parallel combination of $R_{O}$ and the constant phase element (CPE), $Q_{O}$, is taken as an effective description of the oxide ion diffusion and change in oxygen stoichiometry in the LSM phase. The resistance, $R_{c}$, covers the interfacial reactions, i.e. oxygen reduction on the LSM surface and ionic charge transfer from the LSM electrode to the YSZ electrolyte. This reaction path is then shunted by the double layer capacity in terms of the CPE element, $Q_{d}$. Finally, $R_{s}$ is the electrolyte resistance to the counter electrode. Figure $5 \mathrm{~b}$ shows measured and fitted impedance spectra of a $50 \mu \mathrm{m}$ diameter LSM microelectrode measured at different temperatures in air.

As seen in Figure 5b, the high frequency intercept, $R_{s}$, is very small compared to the overall resistance of the electrode reaction $R_{p}=R_{c}+R_{O}$. For a planar circular disc electrode on a solid electrolyte surface the electrolyte resistance is $(9,10)$ :

$$
R_{s}=1 /\left(2 \cdot d \cdot \sigma_{y s z}\right)
$$


where $d$ is the diameter of the microelectrode and $\sigma_{y s z}$ is the ionic conductivity of the electrolyte. To check the functionality of the whole set-up, the ionic conductivity of the YSZ was calculated from Eq. 1 using the $R_{s}$ values obtained by fitting the equivalent circuit to the experimental data shown in Figure 5b. The resulting values ranged from $9.3 \cdot 10^{-3}$ to $5.1 \cdot 10^{-2} \mathrm{~S} / \mathrm{cm}$, and an activation energy for the ionic conduction of the YSZ of $0.86 \pm 0.03 \mathrm{eV}$ in the temperature range of $660-850{ }^{\circ} \mathrm{C}$ was determined, i.e. the results are in good agreement with literature values (11-13).

Figure 5c shows an Arrhenius plot of the corresponding $R_{p}$ for the $50 \mu \mathrm{m}$ diameter LSM microelectrode. An activation energy of $1.87 \mathrm{eV}$ was obtained from linear regression. Previously Takeda et al. have reported an activation energy of $1.87 \mathrm{eV}$ for $\mathrm{LSM}\left(\mathrm{La}_{0.7} \mathrm{Sr}_{0.3} \mathrm{MnO}_{3}\right.$ and $\mathrm{La}_{0.5} \mathrm{Sr}_{0.5} \mathrm{MnO}_{3}$ ) thin film electrodes deposited on YSZ (14). Later Siebert et al. studied $\mathrm{La}_{0.9} \mathrm{Sr}_{0.1} \mathrm{MnO}_{3}$ deposited on YSZ and derived the activation energy of electrode polarization resistance per unit surface area or unit perimeter length of 1.8 - $1.9 \mathrm{eV}$ (15). Recently Huber et al. (16) have separated the activation energy into contributions from the reaction at the TPB and the surface reaction paths on the basis of the temperature dependency of the reaction resistance. They found $0.95 \mathrm{eV}$ for the TPB path and $2.47 \mathrm{eV}$ for the surface reaction path i.e. values below and above those previously reported and that of the present work. This could indicate that the values close to $1.9 \mathrm{eV}$ are determined in potential/temperature regions where both paths are active, and additionally differences in microstructure and segregation of impurities may play a role.

Figure 6a-c show impedance spectra of differently sized LSM microelectrodes measured at $850{ }^{\circ} \mathrm{C}$ in oxygen, air, and nitrogen. To determine whether the electrode impedance reflects an electrode reaction confined to the triple phase boundary (TPB) along the perimeter of the electrode or to the entire electrode-electrolyte interface including diffusion through the electrode, $R_{p}$, can be written as

$$
R_{p}=d^{\alpha} \cdot \text { const }
$$


where $d$ is the electrode diameter. In the case of a pure TPB reaction $\alpha=-1$, whereas $\alpha=-2$ indicates that the reaction is taking place at the LSM-YSZ interface. Figure 6d shows a doublelogarithmic plot of $R_{p}$ determined from impedance fitting versus the microelectrode diameter. The $\alpha$-values equal to the slopes obtained by linear regression are close to one in air and oxygen, showing that $R_{p}$ scales with the inverse of the microelectrode diameter, i.e. with the length of the TPB. In $\mathrm{N}_{2}$, the slope is about -1.66 , indicating that the polarization resistance is related to the inverse of the electrode area, though not completely.

Impedance under polarization. - In order to investigate how the impedance of the LSM microelectrodes is influenced by polarization, measurements were carried out on $50 \mu \mathrm{m}$ diameter LSM microelectrodes at $850{ }^{\circ} \mathrm{C}$ in pure oxygen under polarization. Figure 7 shows the resulting impedance spectra. With anodic polarization the spectra tends to separate into more distinct high and low frequency regions. The electrode polarization resistance is seen to decrease in the anodic as well as the cathodic region, and as shown in Figure $7 \mathrm{~d}, \log \left(R_{p}\right)$ show linear dependencies of the electrode potential in both regions.

Voltammetry. - Cyclic voltammetry was carried out in the potential range $350 \mathrm{mV}$ to $-350 \mathrm{mV}$ with a sweep rate of $1 \mathrm{mV} \mathrm{s}^{-1}$. Figure 8a shows the last of three cycles measured on LSM microelectrodes with diameters ranging from 20 to $100 \mu \mathrm{m}$ at $850{ }^{\circ} \mathrm{C}$ in $\mathrm{N}_{2}\left(p \mathrm{O}_{2} \approx 10^{-4}\right.$ bar). At this sweep rate the curves exhibit a significant hysteresis, inductive at negative potentials and capacitive in the positive potential region. 
As accentuated in Figure 8b, the 20 and $50 \mu \mathrm{m}$ electrodes show a pair of minor peaks, a cathodic peak close to $-300 \mathrm{mV}$ and an anodic peak slightly above $200 \mathrm{mV}$. Similar peaks have previously been observed for LSM containing an excess of manganese and ascribed to the reaction (17):

$$
3 \mathrm{MnO}+\mathrm{O}^{2-} \rightleftharpoons \mathrm{Mn}_{3} \mathrm{O}_{4}+2 e^{-}
$$

From thermodynamic data $(18,19)$ the equilibrium potential for the couple is calculated to $-0.284 \mathrm{~V}$ vs. an oxygen electrode with $\mathrm{pO}_{2}=10^{-4}$ bar at this temperature, i.e. a potential in between the peaks corroborating that they are actually due to the excess of manganese in the LSM. Integrating the excess currents in the peaks yields - in average for the $20 \mu \mathrm{m}$ electrode - a charge of $7.5 \mathrm{nC}$ corresponding to $7 \cdot 10^{-14} / 2=3.5 \cdot 10^{-14} \mathrm{~mol}$ oxygen atoms. On the basis of the electrode dimensions, an LSM density of $6.5 \mathrm{~g} / \mathrm{cm}^{3}$ (20) and a molecular mass of $231.6 \mathrm{~g} / \mathrm{mol}$, the amount of LSM in the electrode calculated to $1.1 \cdot 10^{-12} \mathrm{~mol}$.

The electrode has a nominal excess of $5 \% \mathrm{Mn}$ and therefore $0.05 \cdot 1.1 \cdot 10^{-12} / 3=1.8 \cdot 10^{-14} \mathrm{~mol} \mathrm{O}$ is expected to participate in the reaction. Although the nominal excess of manganese is only half of that corresponding to the amount of oxygen experimentally involved in the redox reaction, the result indicates that the (Sr,La)/Mn ratio of the electrode is close to that of the target used in the PLD process.

To obtain the relative current contributions from the TPB and the surface reaction paths their scaling properties with respect to the electrode dimension are utilized in a way slightly different from the procedure used for the polarization resistance in Figure 6d. It is assumed that the current can be written as the sum of the TPB and the area dependent contributions, i.e. 
$i=i_{T P B}+i_{A}=a \cdot d+b \cdot d^{2}$

where $d$ is the electrode diameter. The coefficients $a$ and $b$ were determined for a number of potential values from the sweeps in Figure 8a by linear regression. The relative contribution from the TPB path to the total current can be calculated as:

$\frac{i_{T P B}}{i}=\frac{a \cdot d}{a \cdot d+b \cdot d^{2}}$

The results calculated for the $100 \mu \mathrm{m}$ electrodes are shown in Figure 8c. As the sweeps show pronounced hysteresis indicating that a steady state has not been achieved, the relative uncertainty of the current values is very large for the small currents close to the equilibrium potential. Therefore, values calculated for the potential region $-100-100 \mathrm{mV}$ are not representative and have been omitted.

The general trend in Figure 8c is that the TPB reaction is dominating at high positive potentials, whereas the surface distributed path supplies most of the current at low potentials. The values obtained, in particular in the cathodic region, show a substantial hysteresis, reflecting the decrease in electrode activity in the anodic region and a slow activity increase in the cathodic sweep. Because of the slow changes in electrode activity the current distributions found when moving from the polarized states towards equilibrium are most likely closer to the steady state than those determined for increasing polarization. The smoothed blue line in Figure $8 \mathrm{c}$ is therefore believed to be a reasonable depiction of the steady state partitioning between the TPB and the surface pathways.

In Figure 8d the sweep current for the $100 \mu \mathrm{m}$ electrode has been split into contributions from the TPB path and the bulk path. Like Figure8d it demonstrates that the bulk path is dominating in the 
cathodic regime whereas the TPB path dominates at large anodic overvoltages, but it is surprising that the TPB path and the bulk path tend to be to be almost closed in the cathodic and the anodic range, respectively.

Obviously, the separation procedure, based on only three experimental values at each potential, has some uncertainty. From the results of the regression it is estimated to be up to $10 \mathrm{nA}$ at high anodic overpotentials and below a $2 \mathrm{nA}$ in the cathodic range, so the picture of a paths opening in one current direction and closing in the other could indicate that also current transferred accumulation/depletion of components at the TPB may play a role.

Scanning electron microscopy. - The sintering of the microelectrodes caused grain growth and morphology changes of both the YSZ and the LSM. After sintering the LSM grain size is 100-500 $\mathrm{nm}$. The surfaces of the microelectrodes are homogeneous with some visible features of the underlying YSZ grain structure, and at the edge a separate phase has formed as discrete particles which are $\sim 1 \mu \mathrm{m}$ wide and several microns long (Figure 9a). TOF-SIMS shows that this phase is Mn poor and La and Si rich compared to the electrode surface.

All microelectrodes exposed to the changing atmosphere and temperatures in CAHT-2 have developed additional features. The smallest electrodes with a diameter of $20 \mu \mathrm{m}$ show a significant change to a coarser microstructures over the entire area (Figure 9b). The larger electrodes show a coarse structure at the outer few microns (Figure 9c). Additionally, they have developed larger grains, up to a few microns long on the electrode surface, primarily positioned along the grain boundaries of the underlying YSZ.

In the following, electrochemically characterized microelectrodes are either electrodes where impedance spectroscopy at OCV has been performed, or microelectrodes that were polarized during impedance spectroscopy or in cyclic voltammetry measurements. A common feature for these electrodes is that the contact area where the probe has touched the electrode seems more porous 
than the surrounding area (Figure9d, e and f). The changes are more severe for electrodes that were polarized and where cyclic voltammetry was performed, and weaker for electrodes subjected to OCV conditions only. For some microelectrodes a part of the electrode adhered to the probe and it was torn out leaving a fracture when the probe was lifted after the measurement. Other electrodes have holes not indicative of fracture (Figure 9e).

Time-of-flight secondary ion mass spectrometry. - The TOF-SIMS analyses show a redistribution of some elements as a result of the treatment in CAHT-2. Whereas the as-sintered microelectrodes show relatively even distributions of $\mathrm{Mn}, \mathrm{Sr}$ and $\mathrm{La}$ on the microelectrode surface, the prolonged exposure to temperature and changing atmospheres caused Mn to migrate outside the electrode, and the formation of Mn poor and La rich discrete particles on the electrode surface.

Figure 10 shows the Mn, Sr and La distribution on four differently treated microelectrodes. The assintered microelectrode has a relatively even distribution of the elements. The microelectrode named OCV shows that Mn has migrated outside the electrode area. As the OCV measurements are not expected to influence the composition, this is ascribed to the effect of temperature and atmosphere only. For polarized electrodes, however, the Mn seems to migrate outside the electrode during cathodic polarization. This occurs to a much lesser extent during anodic polarization.

In all cases where microelectrodes have been exposed to elevated temperatures in CAHT-2 the microelectrode edge is dark in the Mn images, showing lack of Mn in this region, and similarly Mnpoor particles are found on the electrode surface. Figure 11 shows TOF-SIMS images of the edge and the particles of the cathodically polarized microelectrode (C350) from Figure 10. It is recognized that both the edge and the particles are Mn-poor and La- and Si-rich compared to the surrounding electrode surface. 
Several impurity elements such as $\mathrm{Na}, \mathrm{K}, \mathrm{Si}$ and Ca were present on the surface after sintering and electrochemical experiments in CAHT-2, as a covering layer, discrete particles or as a ring located at the TPB region. The distribution of the elements changed during exposure to temperature and atmosphere in CAHT-2 (Figure 12). Na was initially located as particles on the substrate surface and on the electrode surface, and after the electrochemical experiments it was mainly found on the substrate surface and in the contact points. Si had initially segregated to the TPB region during the heat treatment but was later found both in the contact area and also on the substrate. The Si ring has a width of 2-3 $\mu \mathrm{m}$ according to TOF-SIMS images of 100, 50 and $20 \mu \mathrm{m}$ electrodes. Na and Si were distributed differently on YSZ grains with different crystallographic orientation, as can also be observed for the OCV microelectrode in Figure 12.

Conductance mapping. - As expected from the current distribution shown in Figure 4 the assintered microelectrodes typically show a uniform and high conductance distributed over the electrode surface (Figure13 a), whereas the microelectrodes that were exposed to elevated temperatures and changing atmospheres in CAHT-2 show areas of both high (yellow areas) and low conductance (blue areas)(Figure 13b). The low conductance areas are seen both on the electrode surface, and at the perimeter, where the outer few microns of the microelectrodes seem to have a lower conductance than the surrounding YSZ. Additionally, a part of the LSM is missing (Figure 13b, arrow) which was torn out when the probe was lifted after impedance spectroscopy, and the lower conducting YSZ below shows up as the blue area.

\section{Discussion}


The sintering of the microelectrodes for 5 hours in air at $1000{ }^{\circ} \mathrm{C}$ resulted in some morphological changes including formation of a secondary phase, but before exposure to temperature and atmosphere variations and electrochemical measurements in CAHT-2, the surface distribution of $\mathrm{La}, \mathrm{Mn}$ and $\mathrm{Sr}$ was relatively homogeneous as shown by the TOF-SIMS data in Figure 10. Impurities present in the system are mobile and are quickly redistributed during heat treatment. The surface composition of LSM after heat treatment in various atmospheres was investigated by X-ray photoelectron spectroscopy (XPS) by Knöfel et al. (21). No significant changes were detected after 13 days at $1000^{\circ} \mathrm{C}$ in dry air. In dry nitrogen $\mathrm{Sr}$ enrichment was found, pointing to a larger influence of low $\mathrm{pO}_{2}$ on the surface composition.

The microelectrodes were subsequently subjected to a variety of conditions during the many hours of measurements in CAHT-2, spanning from temperature changes to atmospheric changes and polarizations. As Mn segregation from the electrode to the YSZ surface occurs also for samples that were not polarized it indicates that this may originate mainly from high temperature and atmosphere exposure, as also observed previously $(22,23)$. However, the difference in Mn intensity outside the electrode observed for the anodically and cathodically polarized electrodes (Figure 10) may result from polarization. Backhaus-Ricoult et al. (22) found a difference between the anodically and cathodically polarized LSM electrodes during in situ XPS. They observed the diffusion of Mn to the YSZ surface during cathodic polarization and a to some extent reversible retreat of the Mn back to the LSM during anodic polarization. A much more detailed description of the TOF-SIMS data on the LSM microelectrodes including depth profiles can be found elsewhere (24).

The edge of the microelectrode which shows a morphology change and is rich in Si and La corresponds well with the rim of low conductance on the electrode edge. The low conductance questions the actual position of the LSM-YSZ TPB and its length being the perimeter of the original electrode. Also, the SEM image in Figure 9b could indicate the presence of a substantial TPB length 
inside the electrode, which could give an area dependent electrode activity even in the case where the TPB reaction is dominating.

However, Figure 6d shows that in oxygen and air the electrode polarization resistance determined from the impedance is inversely proportional to the electrode diameter corresponding to a reaction at the TPB being dominating. If the TPB is not coinciding with the original perimeter then at least its length scales with the electrode diameter. Thus, there is not a significant contribution from inner TPB zones or, as comparison of Figure 9b and c could indicate, the TPB zones are confined to a zone of a few micrometer along the edge and therefore giving a TPB length proportional to the electrode perimeter.

In general the microelectrodes show substantial changes in chemical, microstructural and electrical properties as a result of the experimental conditions both at the TPB and the electrode surface. Microstructural changes were not previously observed on LSM microelectrodes (2) except for the formation of bubbles at strong anodic polarizations $(1,25)$ and coarsening (25).

In nitrogen with ca. $10^{-4}$ bar $\mathrm{O}_{2}$ the value of $\alpha=-1.66$ indicates a substantial contribution from the interfacial reaction. Comparing these results with the dependencies determined in Figure 8c it is noted that the values obtained at OCV are coinciding. The general trend in Figure 8c is that at high anodic polarizations $\alpha$ values close to -1 are obtained, and decreasing the polarization results in a lower value, reaching an $\alpha$ value of -2 at $-200 \mathrm{mV}$. A polarization of $-200 \mathrm{mV}$ in $\mathrm{N}_{2}$ with $10^{-4}$ bar $\mathrm{O}_{2}$ corresponds to an equilibrium oxygen pressure in the order of $10^{-7}$ bar, whereas $250 \mathrm{mV}$ is roughly equivalent to air. Thus, in this potential range LSM with 20-30 \% Sr substitution of La changes from a slight excess of oxide ions to become clearly oxygen deficit, i.e. the oxide ion vacancy concentration becomes significant (17) and an increase in the oxide ion diffusion coefficient is expected. This implies that the transition from the TPB to the interfacial reaction path is due to an increase of the oxide ion diffusion rate at low potentials favoring the reaction where oxygen is 
reduced at the outer electrode surface and the oxide ions diffuse through the LSM electrode to the electrode-electrolyte interface.

This behavior can also explain the hysteresis in the voltammograms in Figure 8a. Starting at $0 \mathrm{mV}$ and moving in the positive potential direction the oxide ion diffusion coefficient decreases with the increasing oxygen content of the LSM. Due to the relatively high sweep rate the LSM stoichiometry lags behind the equilibrium value and therefore - at a given potential - the diffusion coefficient is lower on the return from the maximum potential and consequently a decrease in current or a capacitive hysteresis is seen. Continuing the sweep toward negative potentials the oxide ion diffusion coefficient increases and numerically larger currents are obtained on the return path and an inductive hysteresis in the order of $50 \mathrm{mV}(\sim 50 \mathrm{~s})$ is observed. The characteristic frequencies of the low frequency arcs in Figure $6 \mathrm{~b}$ are within the range $2-5 \cdot 10^{-2} \mathrm{~Hz}$ corresponding to a time constant of 20-50 s. So, although there is no simple way to compare hysteresis in sweeps with impedance frequencies, the results appear consistent.

From the value at $850^{\circ} \mathrm{C}$ of $\ln (10) \mathrm{RT} / \mathrm{F}=0.223 \mathrm{~V}$ and the slopes given in Figure $7 \mathrm{~d}$ the values of $\mathrm{dU} / \mathrm{d} \log \left(\mathrm{R}_{\mathrm{p}}\right)$ are, in units of $\ln (10) \mathrm{RT} / \mathrm{F}$, calculated to $1 /(0.223 \cdot \alpha)=1.04$ for the cathodic range, 0.86. for the anodic range below $200 \mathrm{mV}$ and -0.34 above $200 \mathrm{mV}$. Although the values close to unity could be interpreted as Tafel slopes for a two-electron transfer reaction, the fact that they are observed in the potential region usually considered as linear with respect to the current-voltage relation is more likely to point towards an activation mechanism induced by secondary processes. As $\mathrm{d} U / \mathrm{d} \log \left(R_{p}\right)$ is found to be in the order of $\ln (10) R T / F$, a property like the thermodynamic change in the $\mathrm{Mn}^{+4} / \mathrm{Mn}^{+3}$ might be the reason. However, the sign of the slope changes at the equilibrium potential and the decrease in polarization resistance must therefore be caused by the overvoltage or the current itself. A similar non-linear activation mechanism, still not understood, has previously been observed for LSM (26) as well as Pt point electrodes on YSZ (27, 28). 
The order of magnitude of the calculated area-specific capacitance of $100 \mu \mathrm{F} \mathrm{cm}{ }^{-2}$ and $1 \mathrm{mF} \mathrm{cm}^{-2}$ for the high and low frequency arc, respectively, points to the LSM-YSZ interface for the high frequency arc(s) and changes in the LSM stoichiometry for the low frequency arc. The value for the change in stoichiometry, the chemical capacitance, is in close agreement with the $400 \mu \mathrm{F} \mathrm{cm}^{-2}$ determined by Fleig et al. (2) for an LSM electrode with a thickness of $250 \mathrm{~nm}$, i.e. half the thickness of the electrodes in the present work.

Takeda et al. (14) found $R_{p} \approx 10^{3} \Omega \mathrm{cm}^{2}$ at $800{ }^{\circ} \mathrm{C}$ in air and an activation energy of $1.87 \mathrm{eV}$ for large circular $\mathrm{La}_{0.7} \mathrm{Sr}_{0.3} \mathrm{MnO}_{3}$ thin film electrodes with $12 \mathrm{~mm}$ diameter and $2 \mu \mathrm{m}$ thickness. Their electrodes were sintered for $5 \mathrm{~h}$ at $800{ }^{\circ} \mathrm{C}$ before test at the same temperature. If their $R_{p}$ is recalculated to line specific resistance instead it gives ca. $3.3 \cdot 10^{3} \Omega \mathrm{cm}$ compared to ca. $7 \cdot 10^{5} \Omega \mathrm{cm}$ at $810{ }^{\circ} \mathrm{C}$ found here for $\left(\mathrm{La}_{0.75} \mathrm{Sr}_{0.25}\right)_{0.95} \mathrm{MnO}_{3}$ sintered for $5 \mathrm{~h}$ at $1000{ }^{\circ} \mathrm{C}$. The considerable variation may be caused by several differences in the preparation and the geometry of the two sets of electrodes.

The absolute values of the slopes of $\log \left(R_{p}\right)$ versus $\log (d)$ determined in the present work are all smaller than those reported by Fleig et al. (2). The difference may be ascribed to different experimental conditions: $850{ }^{\circ} \mathrm{C}$ versus $800{ }^{\circ} \mathrm{C}$, the thicknesses of 100 and $250 \mathrm{~nm}$ versus $500 \mathrm{~nm}$ of the LSM microelectrodes and possibly a number of other details that we are not aware of. An important question is how sensitive the nature of the segregations is with respect to experimental conditions and time. Recently, it has been shown that the segregations actually are very dependent on temperature and composition (29).

\section{Conclusion}


The influence of oxygen partial pressure and polarization on the electrical characteristics of LSM microelectrodes was investigated. Circular LSM microelectrodes with a nominal composition of $\left(\mathrm{La}_{0.75} \mathrm{Sr}_{0.25}\right)_{0.95} \mathrm{MnO}_{3}$ were prepared on polished YSZ pellets. The electrochemical measurements were carried out using a CAHT-SPM for contacting the electrodes and for impedance spectroscopy and cyclic voltammetry at different temperatures in air, $\mathrm{N}_{2}$ and $\mathrm{O}_{2}$. Below $\mathrm{OCV}$, the polarization resistance of the LSM microelectrodes scales with the inverse of the microelectrode diameter in air and pure oxygen, while in $\mathrm{N}_{2}$ with $\mathrm{pO}_{2} \approx 10^{-4}$ bar it scales more with the inverse of the electrode area though only completely at cathodic polarization corresponding to $p \mathrm{O}_{2}=10^{-6}$ bar or lower. This transition from a TPB constricted reaction zone at high oxygen partial pressures to a reaction covering the entire electrode at pressures where the LSM is oxygen deficit is confirmed by cyclic voltammetry. Microelectrodes may be a good way of studying electrode materials; however, fabrication of microelectrodes with properties comparable to realistic electrodes is a challenge. The present study shows that although microelectrodes have a simple geometry they are not ideal homogeneous entities, and to elucidate the electrochemical properties of the TPB supplementary structural and compositional information is definitely required.

\section{Acknowledgment}

This work was supported financially by The Program Commission on Sustainable Energy and Environment, The Danish Council for Strategic Research, via the Strategic Electrochemistry Research Center (SERC) (www.serc.dk), contract no. 2104-06-0011, and by The Catalysis for Sustainable Energy (CASE) initiative funded by the Danish Ministry of Science, Technology, and Innovation.

\section{References}


1. V. Brichzin, J. Fleig, H.-U. Habermeier, G. Cristiani, and J. Maier, Solid State Ionics, 152153, 499-507 (2002).

2. J. Fleig, H. R. Kim, J. Jamnik, and J. Maier, Fuel Cells, 08, 330-337 (2008).

3. G. J. la O', B. Yildiz, S. McEuen, and Y. Shao-Horn, J. Electrochem. Soc., 154, B427-B438 (2007).

4. G. J. la O' and Y. Shao-Horn, Electrochem. and Solid-State Lett., 12, B82-B85 (2009).

5. Y. Wu, K. V. Hansen, K. Norrman, T. Jacobsen, and M. B. Mogensen, ECS Trans., 57, 16731682 (2013).

6. C. Mack, Fundamental principles of optical lithography: The science of microfabrication, John Wiley and Sons Ltd., Chichester (2007).

7. K. V. Hansen, Y. Wu, T. Jacobsen, M. B. Mogensen, and L. Theil Kuhn, Rev. Sci. Instrum., 84, 073701-073701-7 (2013).

8. K. V. Hansen, C. Sander, S. Koch, and M. Mogensen, J. Phys. Conf. Ser., 61, 389-393 (2007).

9. J. Newman, J. Electrochem. Soc., 113, 501-503 (1966).

10. R. Holm, Stationary Contacts, Springer-Verlag, Berlin (1967).

11. T. Ishihara, N. M. Sammes, and O. Yamamoto, in: High temperature solid oxide fuel cells fundamentals, design and applications, Elsevier (2003).

12. J. Kilner and B. C. H. Steele, in: Nonstoichiometric oxides, Academic Press, London (1981).

13. C. C. Appel, N. Bonanos, A. Horsewell, and S. Linderoth, J. Mater. Sci., 36, 4493-4501 (2001).

14. Y. Takeda, R. Kanno, M. Noda, Y. Tomida, and O. Yamamoto, J. Electrochem. Soc., 134, 2656-2661 (1987).

15. E. Siebert, A. Hammouche, and M. Kleitz, Electrochim. Acta, 40, 1741-1753 (1995).

16. T. M. Huber, M. Kubicek, A. Opitz, and J. Fleig, J. Electrochem. Soc., 162, F229-F242 (2015).

17. B. Zachau-Christiansen, T. Jacobsen, and S. Skaarup, in: Proc. of the $17^{\text {th }}$ Risø International Symposium on Materials Science, F. W. Poulsen, N. Bonanos, S. Linderoth, M. Mogensen, and B. Zachau-Christiansen, Editors, p. 497, Roskilde (1996).

18. K. T. Jacob, A. Kumar, G. Rajitha, and Y. Waseda, High Temp. Mater. Proc., 30, 459-472 (2011).

19. K. T. Jacob, A. Kumar, and Y. Waseda, J. Phase Equilib. Diffus., 29, 222-230 (2008).

20. T. J. Armstrong and A. V. Virkar, J. Electrochem. Soc., 149, A1565-A1571 (2002).

21. C. Knöfel, M. Chen, and M. Mogensen, Fuel Cells, 11, 669-677 (2011).

22. M. Backhaus-Ricoult, K. Adib, T. StClair, B. Luerssen, L. Gregoratti, and A. Barinov, Solid State Ionics, 179, 891-895 (2008).

23. A.-K. Huber, S. O. Steinmüller, E. Mutoro, B. Luerssen, and J. Janek, Diffusion Fundamentals, 12, 52-53 (2010).

24. K. Norrman, K. V. Hansen, T. Jacobsen, Y. Wu, and M. B. Mogensen (in prep.).

25. A.-K. Huber, M. Falk, M. Rohnke, B. Luerssen, M. Amati, L. Gregoratti, D. Hesse, and J. Janek, J. Catal., 294, 79-88 (2012).

26. M. Odgaard and E. Skou, Solid State Ionics, 86-88, 1217-1222 (1996).

27. M. Juhl, M. B. Mogensen, T. Jacobsen, B. Zachau-Christiansen, N. Thorup, and E. Skou, in: Proc. of the $4^{\text {th }}$ International Symposium on SOFC, SOFC-IV, M. Dokiya, O. Yamamoto, H. Tagawa, and S. C. Singhal, Editors, p. 554, The Electrochemical Society Proceedings Series, Pennington, NJ (1995).

28. T. Jacobsen, B. Zachau-Christiansen, L. Bay, and M. J. Jørgensen, Electrochim. Acta, 46, 1019-1024 (2001). 
29. W. Lee, J. W. Han, Y. Chen, Z. Cai, and B. Yildiz, J. Am. Ceram. Soc., 135, 7909-7925 (2013). 


\section{Figure captions}

Figure 1. a) Thickness of the deposited LSM layer measured by a Dektak profilometer. b) SEM image of the cross section of an LSM film.

Figure 2 AFM images showing overview (a) and surface morphology (b) of a $50 \mu \mathrm{m}$ diameter assintered LSM microelectrode.

Figure 3. Schematic of a CAHT-SPM.

Figure 4. Current distributions for a probe tip in contact with a) electrolyte b) microelectrode.

Figure 5. a) Equivalent circuit, b) Impedance spectra of a $50 \mu \mathrm{m}$ diameter LSM microelectrode measured at $660-850{ }^{\circ} \mathrm{C}$ in air. c) Arrhenius plot of the $R_{p}$ values derived from fitting the spectra in b), yielding an activation energy of $1.87 \mathrm{eV}$.

Figure 6. Impedance spectra of LSM microelectrodes measured at OCV at $850{ }^{\circ} \mathrm{C}$ in a) oxygen, b) nitrogen and c) air, and d) a double-logarithmic plot of $R_{p}$ versus the microelectrode diameter, $d$. 
Figure 7. Impedance spectra of $50 \mu \mathrm{m}$ diameter LSM microelectrodes at $850{ }^{\circ} \mathrm{C}$ in pure oxygen measured under a) and b) anodic polarization, and c) under cathodic polarization. d) shows $\log \left(R_{p}\right)$ dependency of electrode potential.

Figure 8. a) Cyclic voltammograms obtained from electrodes with diameters 20, 50 and $100 \mu \mathrm{m}$ at $850{ }^{\circ} \mathrm{C}$ in $\mathrm{N}_{2}\left(\mathrm{pO}_{2} \approx 10^{-4} \mathrm{bar}\right)$; sweep rate $1 \mathrm{mV} \mathrm{s}^{-1}$. b) A part of the voltammograms for the 20 and $50 \mu$ m electrodes, including a 10x magnification of the curve for the $20 \mu \mathrm{m}$ electrode (right axis). c) The relative contribution from the triple phase boundary to the overall reaction for a $100 \mu \mathrm{m}$ electrode calculated from Eq. 4. The blue line is an estimate of the steady state behavior. d) Sweep current contributions from the TPB path and the bulk path.

Figure 9. SEM (SE) images of microelectrodes. a) $20 \mu \mathrm{m}$, as-sintered, arrows show the particles at the edge, b) $20 \mu \mathrm{m}$, exposed in CAHT-2 but not touched, c) $50 \mu \mathrm{m}$, exposed but not touched, arrows show the coarse phase, d) $50 \mu \mathrm{m}$, impedance under polarization up to $\pm 350 \mathrm{mV}$ (arrows show contact points), e) $100 \mu \mathrm{m}$, cyclic voltammetry, arrows show contact points, f) $100 \mu \mathrm{m}$, arrows show probe contacts, impedance under polarization, $-350 \mathrm{mV}$.

Figure 10. $\mathrm{Mn}, \mathrm{Sr}$ and $\mathrm{LaO}$ distributions on an as sintered microelectrode (ASM) and on microelectrodes where impedance spectroscopy at OCV (OCV) and/or cyclic voltammetry and impedance spectroscopy under cathodic or anodic polarization of maximum $\pm 350 \mathrm{mV}$ was carried out (C350 and A350). All microelectrodes are $100 \mu \mathrm{m}$ in diameter. Black arrows show contact points. Light blue arrow shows a defect from sample preparation. Bright colors indicate a high 
intensity, and dark colors indicate a low intensity from an element. The total time spent in CAHT-2 at temperatures between 660 and $850^{\circ} \mathrm{C}$ was $200 \mathrm{~h}$. The time under polarization $( \pm 100 \mathrm{mV}$ to \pm 350 mV) was 200 min for the A350 and 180 min for the C350.

Figure 11. Mn-poor, La- and Si-rich particles and edge on a microelectrode subjected to a maximum polarization of $-350 \mathrm{mV}$ (C350). Bright colors indicate a high intensity, and dark colors indicate a low intensity from an element. The total time spent in CAHT-2 at temperatures between 660 and $850{ }^{\circ} \mathrm{C}$ was $200 \mathrm{~h}$. The time under polarization $( \pm 100 \mathrm{mV}$ to $\pm 350 \mathrm{mV}$ ) was $200 \mathrm{~min}$ for the anodically polarized microelectrode and $180 \mathrm{~min}$ for the cathodically polarized microelectrode.

Figure 12. TOF-SIMS images of Si and Na distribution on $100 \mu \mathrm{m}$ electrodes after sintering, and after impedance spectroscopy at OCV. The arrow points to the ring of Si located in the TPB region. Bright colors indicate a high intensity, and dark colors indicate a low intensity from an element. The total time spent in CAHT-2 at temperatures between 660 and $850{ }^{\circ} \mathrm{C}$ was $200 \mathrm{~h}$ for the OCV sample.

Figure 13. Conductance maps obtained at $650{ }^{\circ} \mathrm{C}$ in air of a) an as-sintered microelectrode and b) a microelectrode subjected to a maximum polarization of $-350 \mathrm{mV}$ during impedance spectroscopy. Both microelectrodes are $50 \mu \mathrm{m}$ in diameter. The arrow in b) points to where a part of the electrode was torn out as a result of the probe contact. 

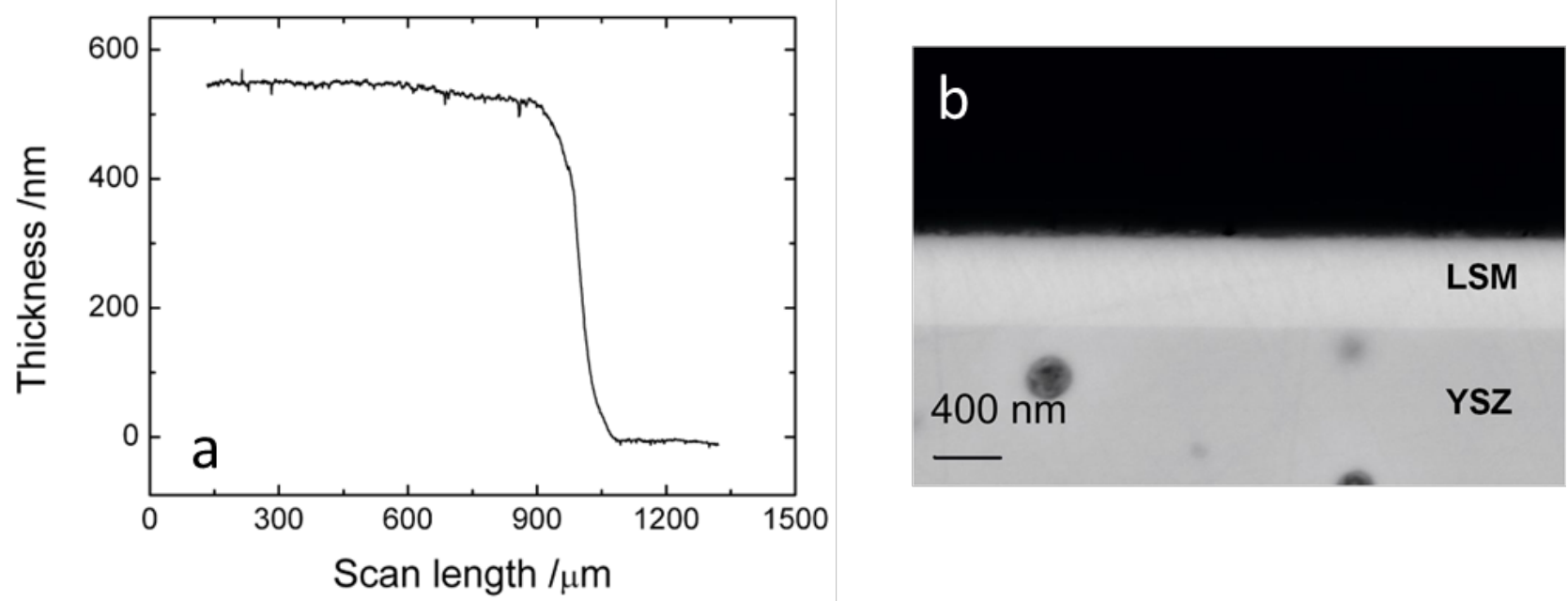

Fig.1 


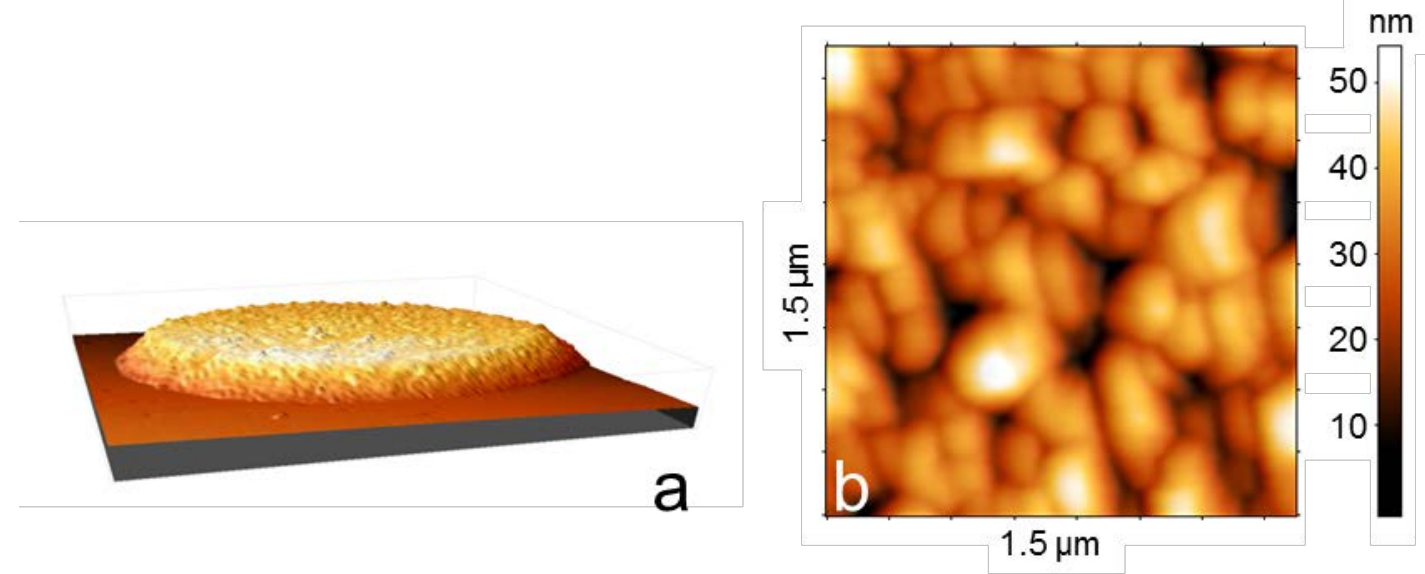

Fig. 2 


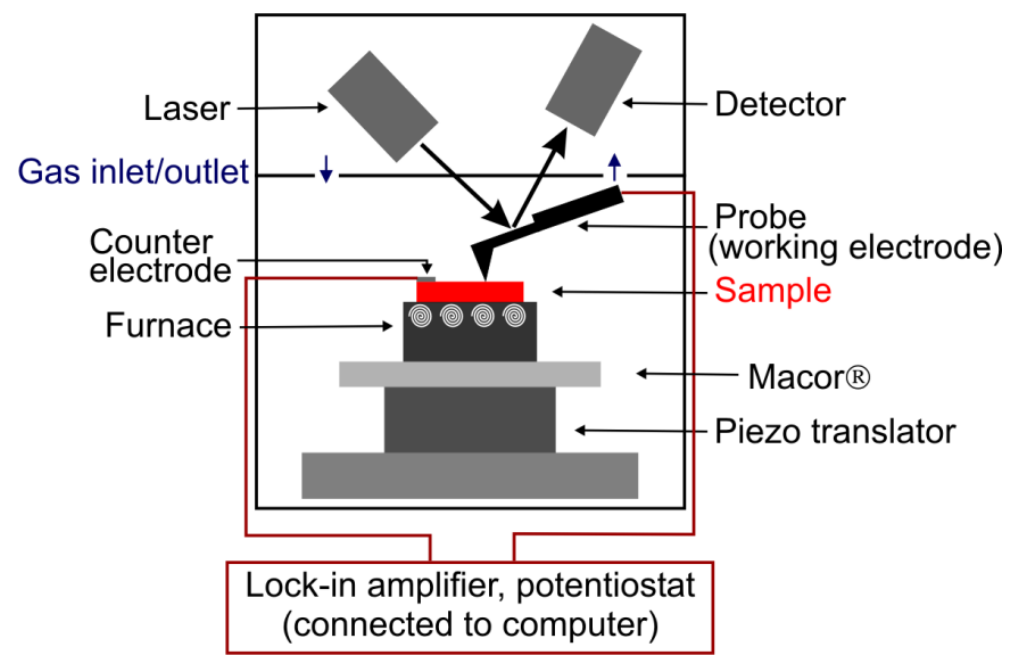

Fig. 3 

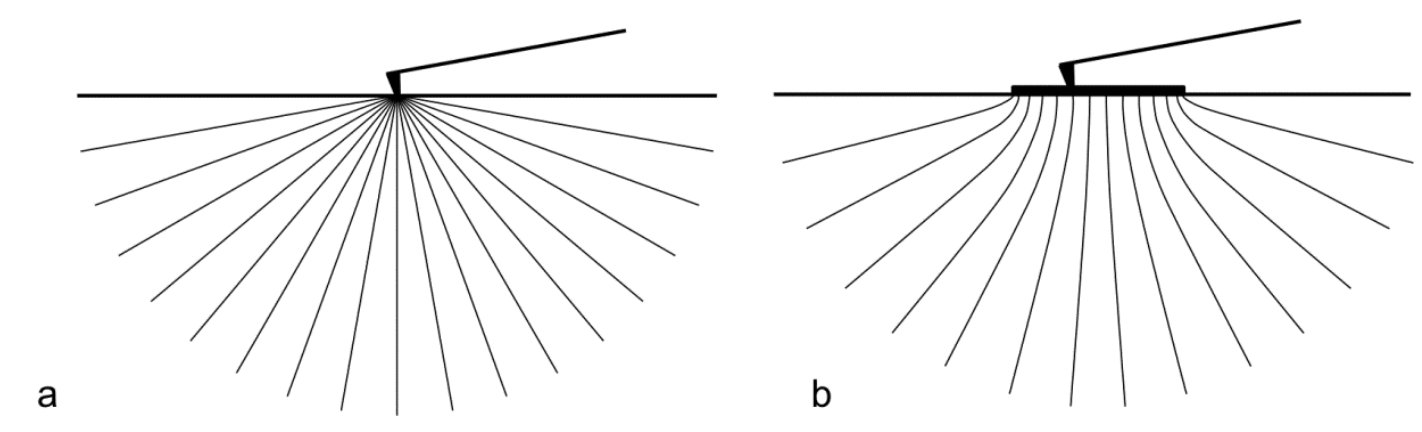

Fig. 4 

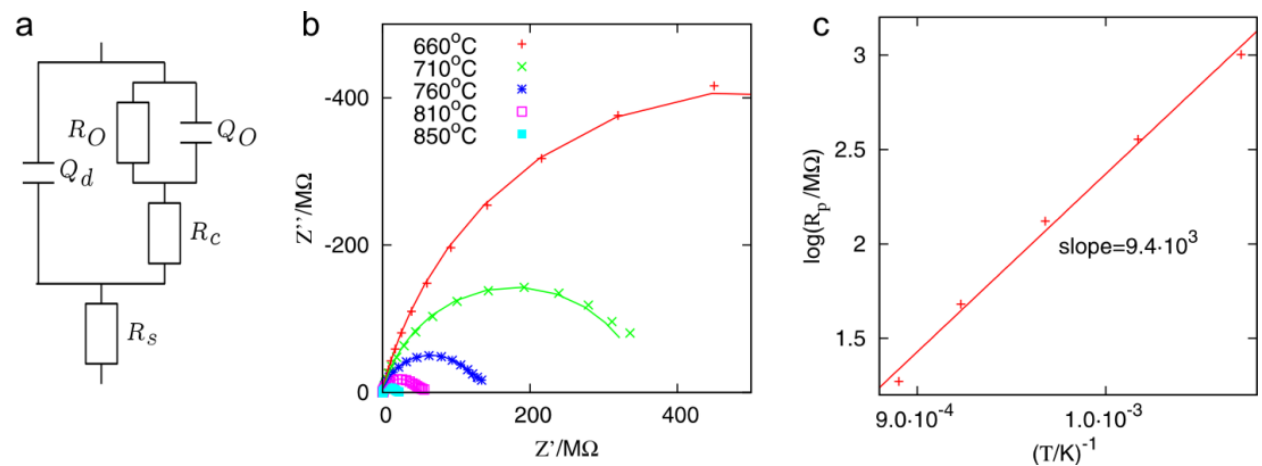

Fig.5 

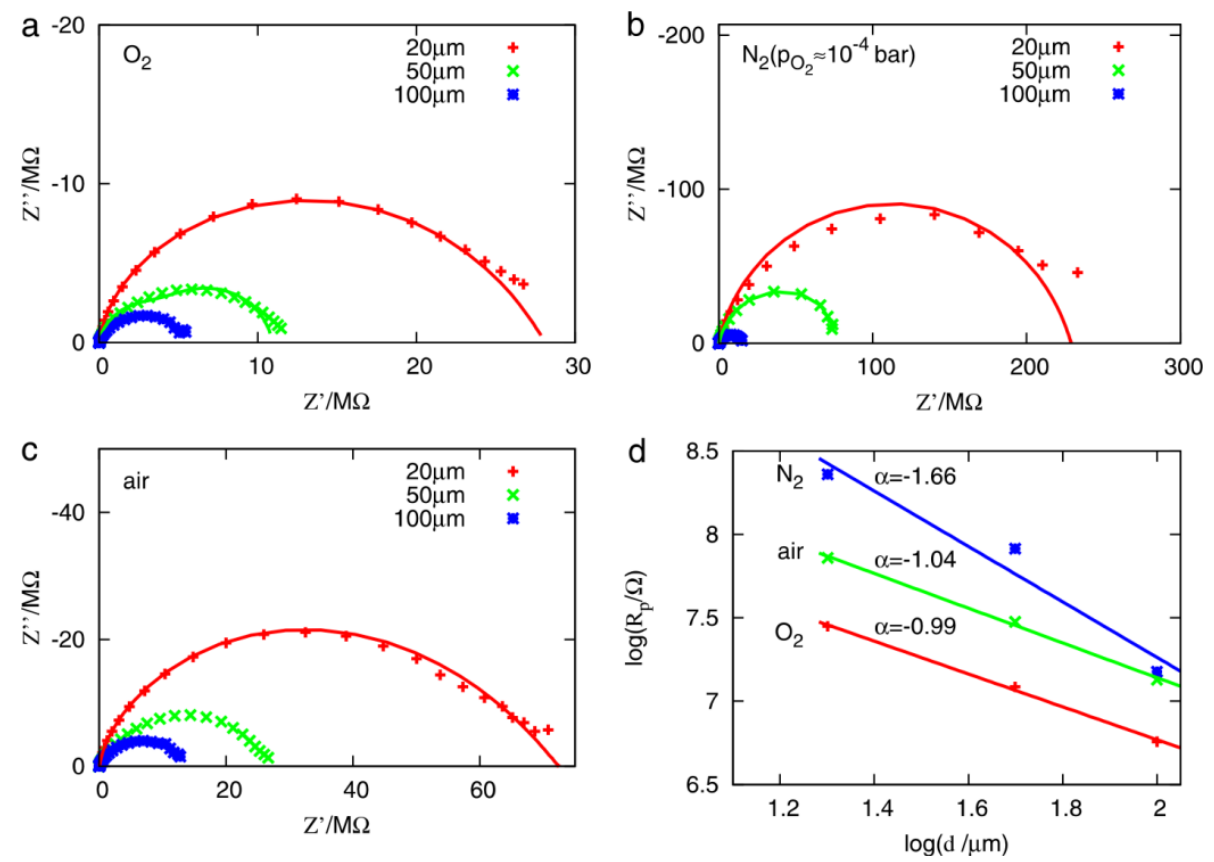

Fig.6 

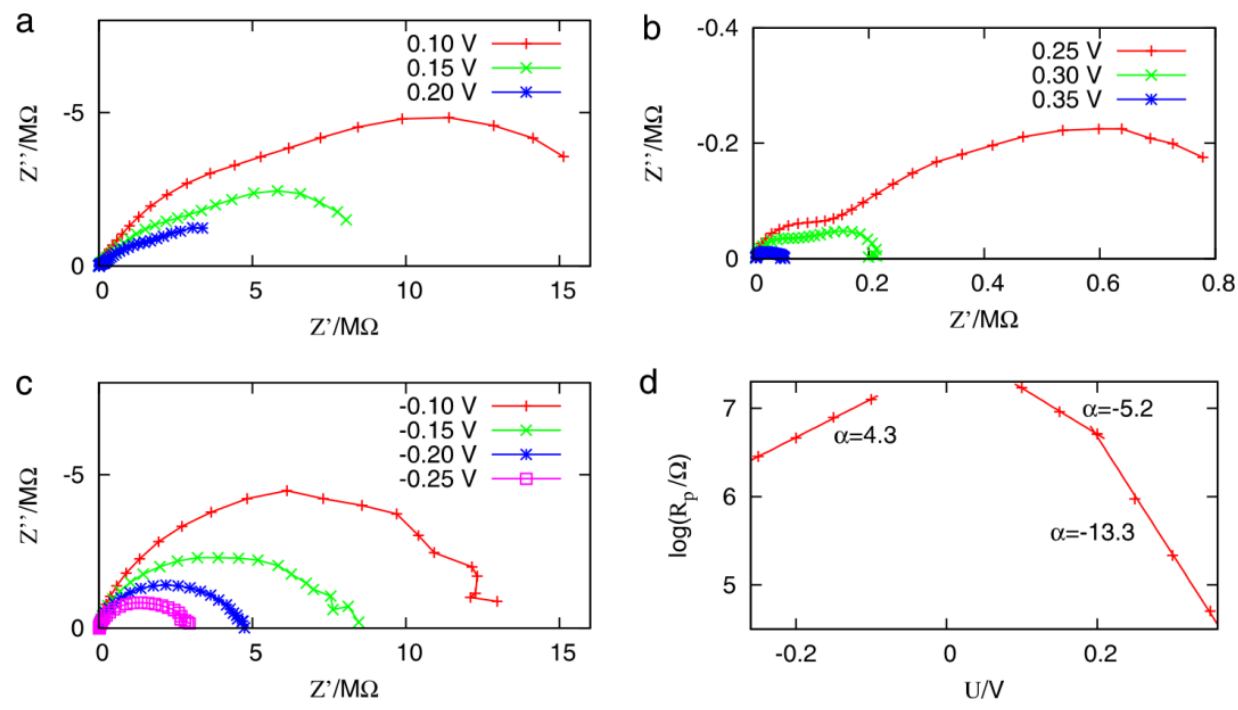

Fig. 7 

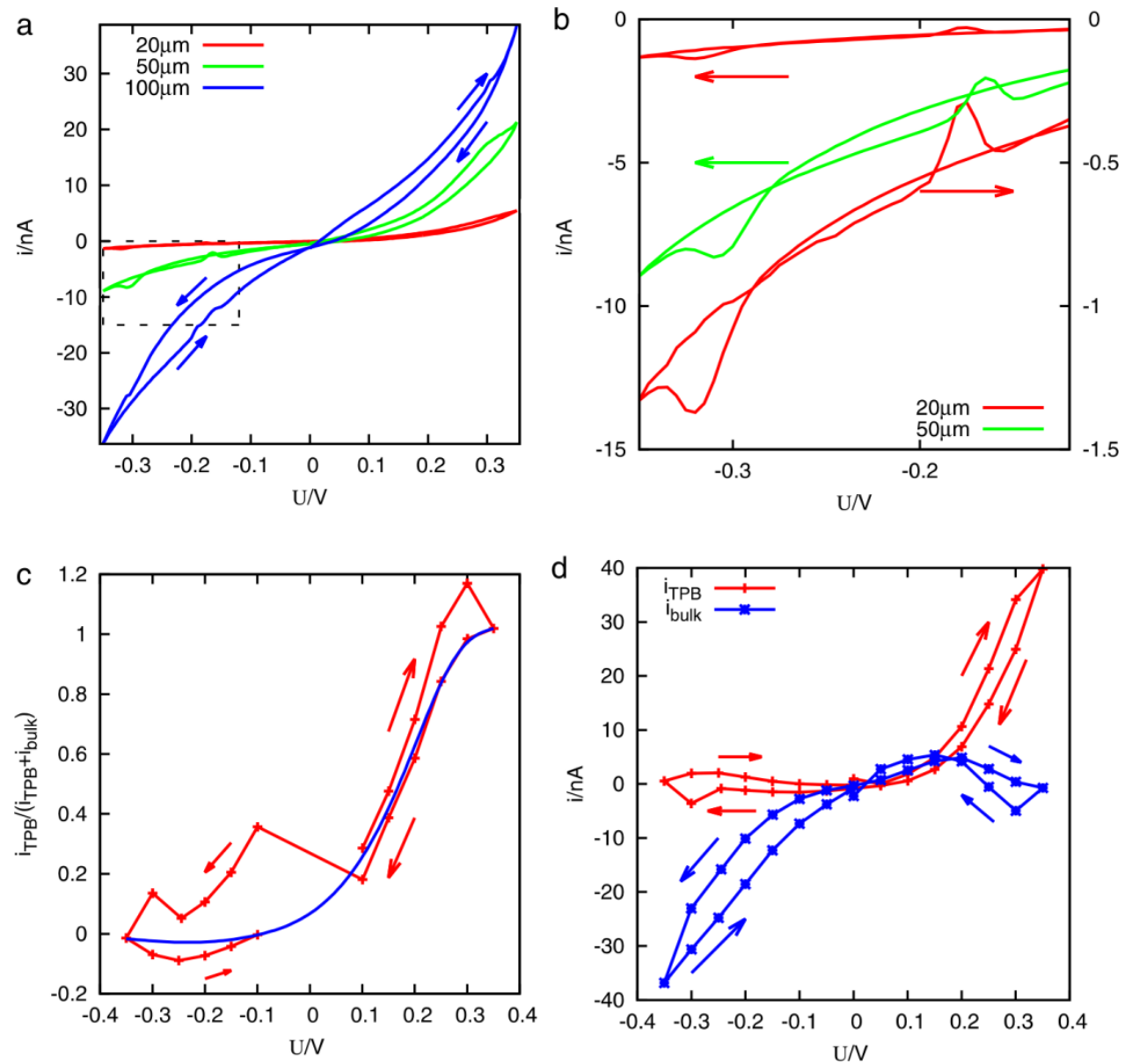

Fig. 8 

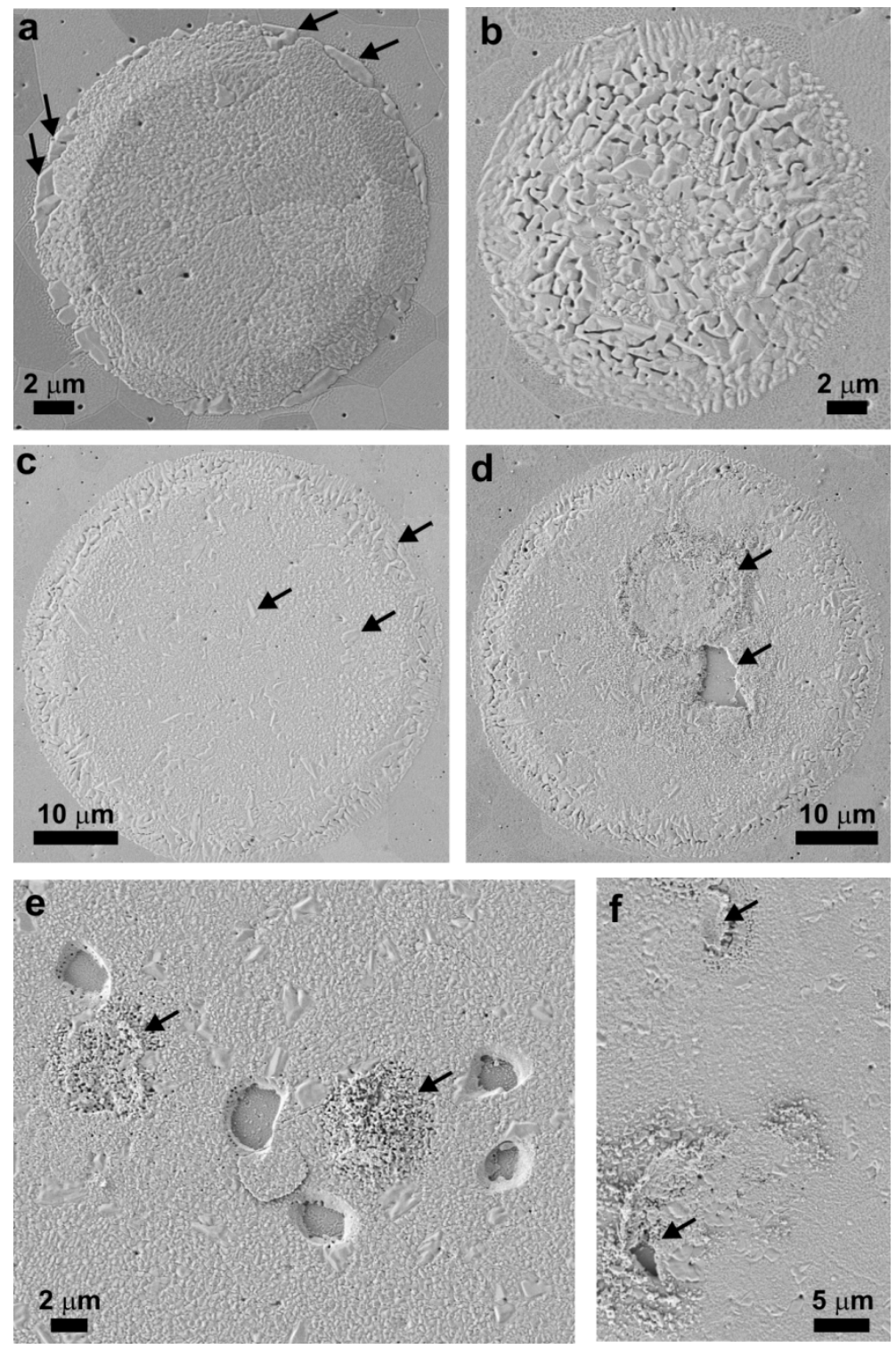

Fig. 9 


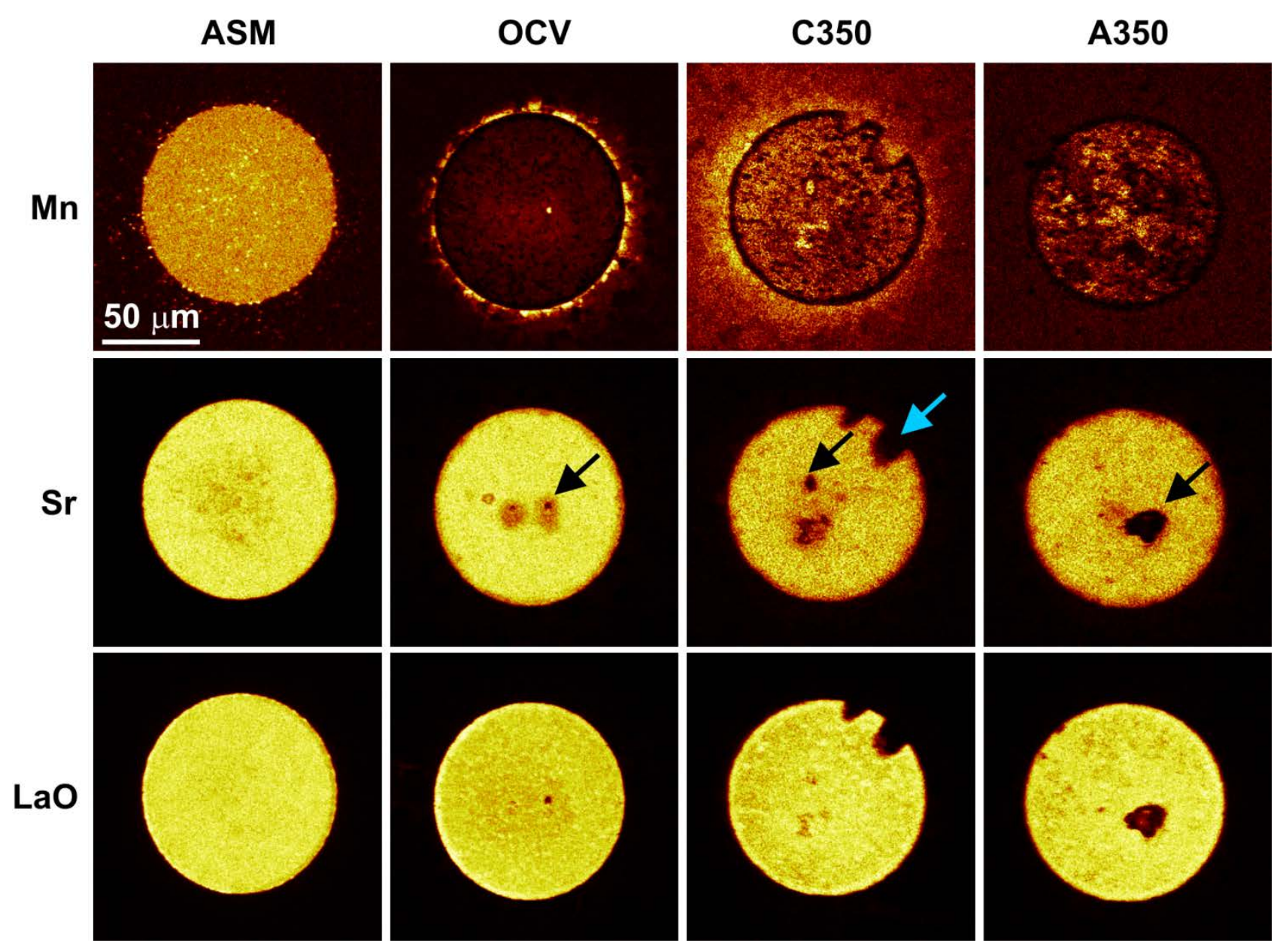

Fig. 10 


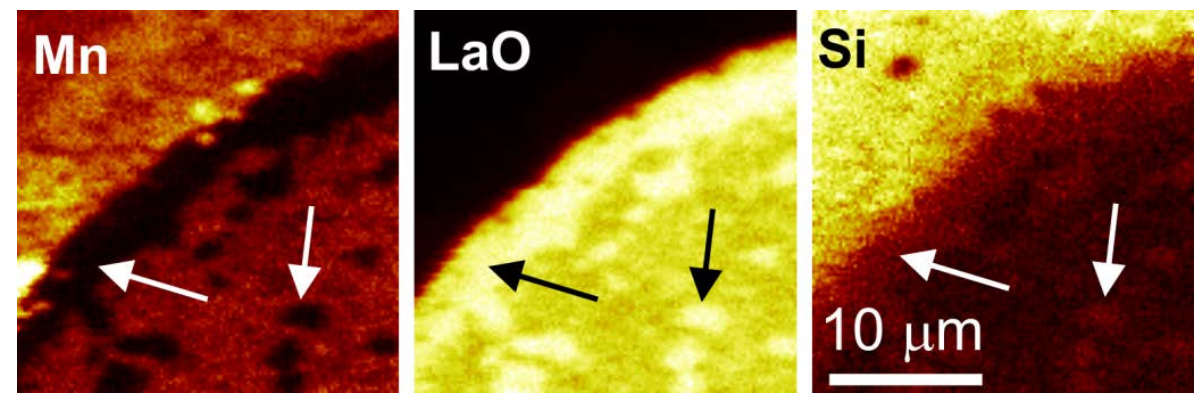

Fig. 11 


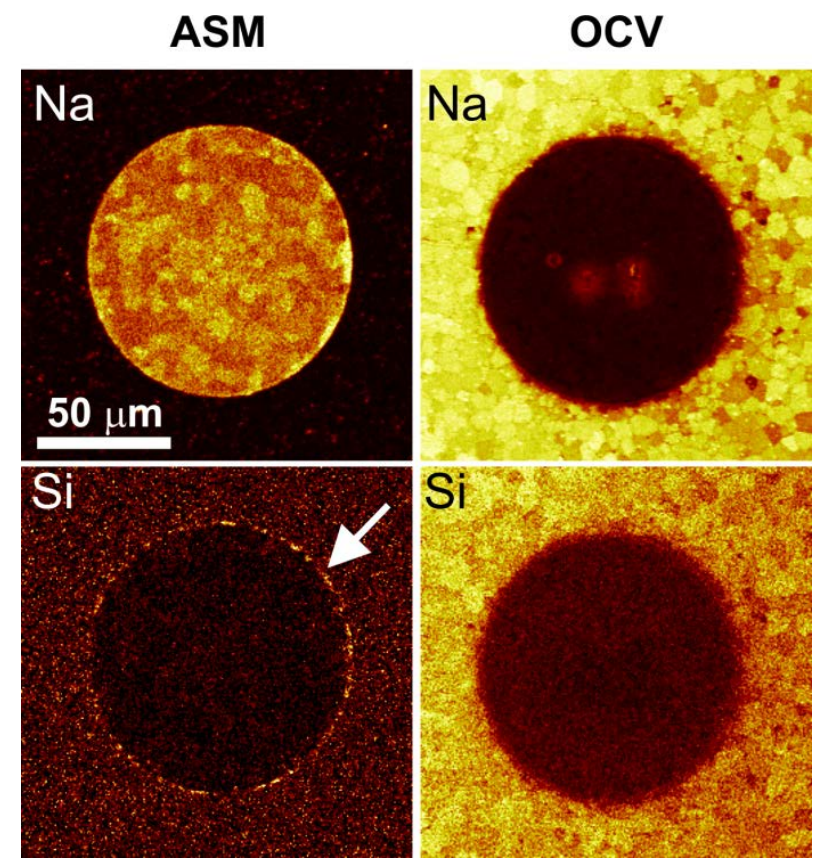

Fig. 12 


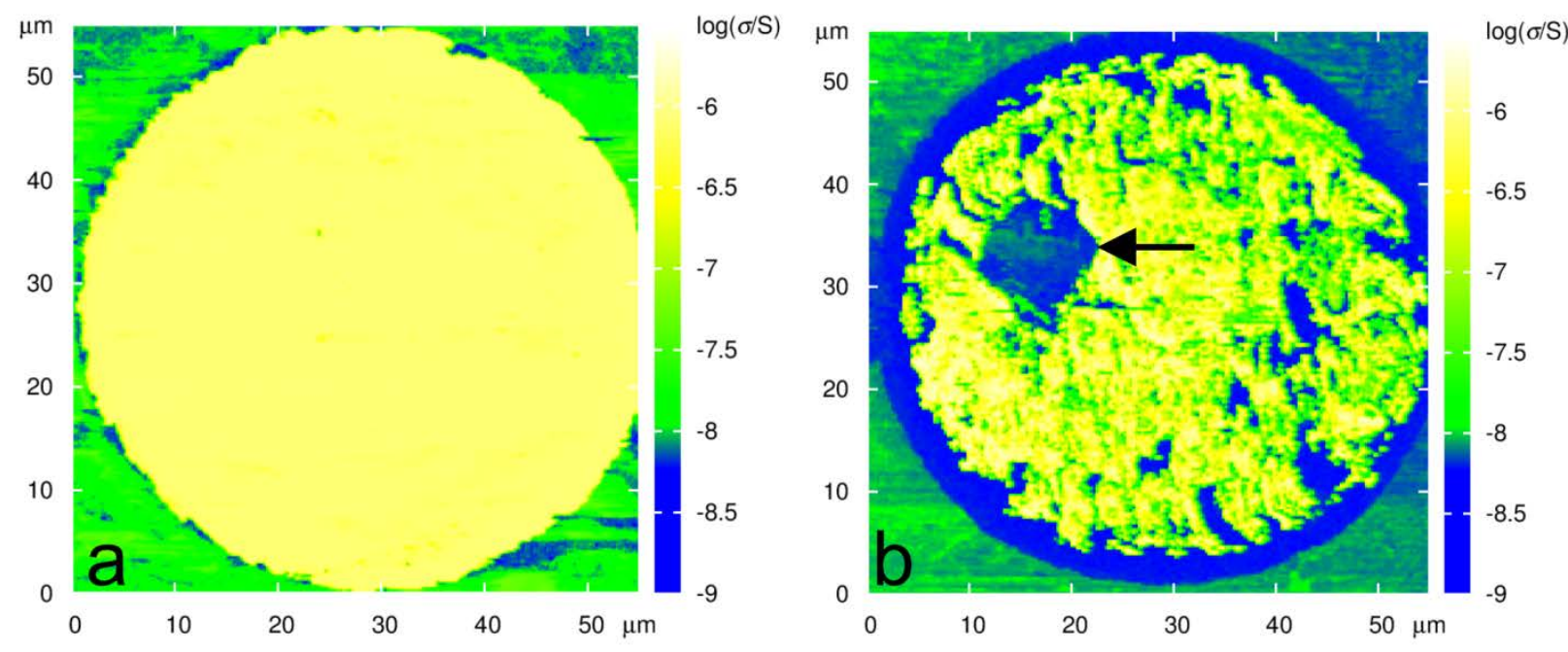

Fig. 13 